\title{
Cardiometabolic risk factors in Iranians with spinal cord injury: Analysis by injury-related variables
}

\author{
Hadis Sabour, MD, PhD; ${ }^{1}$ Abbas Norouzi Javidan, PhD; ${ }^{1}$ Neda Ranjbarnovin, $\mathrm{MD} ;{ }^{2}$ Mohammad Reza Vafa, \\ PhD, MSPH; ${ }^{3}$ Zahra Khazaeipour, MD; ${ }^{1}$ Firoozeh Ghaderi, BSc; ${ }^{1}$ Fatemeh Khanzadeh Mehrabani, BSc; ${ }^{1}$ \\ Farzad Shidfar, PhD, MSc ${ }^{3^{*}}$ \\ ${ }^{1}$ Brain and Spinal Injury Research (BASIR) Center, Imam Khomeini Hospital Complex, Tehran University of Medical \\ Sciences, Tehran, Iran; ${ }^{2}$ Tehran University of Medical Sciences, Tehran, Iran; ${ }^{3}$ School of Public Health, Iran Univer- \\ sity of Medical Sciences, Tehran, Iran
}

\begin{abstract}
Persons with spinal cord injury (SCI) have a high prevalence of abnormalities in carbohydrate and lipid metabolism. These abnormalities cause adverse coronary heart disease (CHD) in patients with SCI. In this study, we performed a detailed analysis of the level-specific cardiometabolic risk factors in individuals with SCI and analyzed the association of injury level on these risk factors. This was a cross-sectional study of 162 patients with SCI, assessing the prevalence of diabetes mellitus, dyslipidemia, hypertension, obesity, and smoking. Fasting blood sugar $(>100)$ was diagnosed in 27 patients $(16.7 \%)$. Of the total patients, $36(22.2 \%)$ had a total cholesterol (TC) level of $>200$. A triglyceride level of $>150$ was present in 56 patients (34.6\%). Hypertension was present in $2.5 \%$ of the entire patient group. Body mass index (BMI), TC, and low-density lipoprotein cholesterol (LDL-C) were significantly higher in the paraplegia group than the tetraplegia group $(24.44+/-4.23$ vs $22.65+/-$ $4.27, p=0.01 ; 185.71+/-40.69$ vs $163.28+/-37.92, p<0.001$; and $102.51+/-28.20$ vs $89.15+/-22.35, p=0.01$, respectively). Patients with paraplegia may have increased hypertension, higher BMI, and increasing levels of serum LDL-C and TC than those with tetraplegia. Conventional risk factors for CHD should be identified and treated in individuals with SCI.
\end{abstract}

Key words: body mass index, cardiometabolic risk factors, cholesterol, coronary heart disease, fasting blood sugar, hypertension, lipid profile, paraplegia, spinal cord injury, tetraplegia.

\section{INTRODUCTION}

Spinal cord injury (SCI) predisposes an individual to medical complications such as obesity, lipid abnormalities, carbohydrate intolerance, and an atherogenic pattern for coronary heart disease (CHD) [1]. Cardiometabolic syndrome is defined through a clustering of cardiovascular risk factors, identified as overweight/obesity, dyslipidemia, hypertension, and insulin resistance [2-3]. It is also thought to better characterize cardiovascular disease (CVD) and endocrine risks [4].

Abbreviations: BASIR $=$ Brain and Spinal Injury Research, $\mathrm{BMI}=$ body mass index, $\mathrm{BP}=$ blood pressure, $\mathrm{CHD}=$ coronary heart disease, $\mathrm{CVD}=$ cardiovascular disease, $\mathrm{DM}=$ diabetes mellitus, FBS = fasting blood sugar, HDL-C = high-density lipoprotein cholesterol, IGT = impaired glucose tolerance, LDL-C = low-density lipoprotein cholesterol, SBP = systolic blood pressure, $\mathrm{SCI}=$ spinal cord injury, $\mathrm{TC}=$ total cholesterol, $\mathrm{TG}=$ tryglyceride, $\mathrm{WC}=$ waist circumference.

*Address all correspondence to Farzad Shidfar, PhD, MSc; Nutrition Department, School of Public Health, Tehran University of Medical Sciences, No. 52, Alvand Ave, Argantine Square, Tehran, Iran; 0098-21-88779118; fax: 0098-2188779487. Email: f-shidfar@tums.ac.ir http://dx.doi.org/10.1682/JRRD.2012.01.0020 
Because of their relative inactivity and adverse body composition changes [5-6], persons with SCI are predisposed to increased rates of impaired glucose tolerance (IGT), insulin resistance and diabetes mellitus (DM) [7], reduced high-density lipoprotein cholesterol (HDL-C) (20\%-42\% lower than in nondisabled persons) [8-9], high low-density lipoprotein cholesterol (LDL-C) [8-10], and increased serum triglyceride (TG) $(6 \%-60 \%$ higher than in nondisabled persons) $[6,8-9]$.

Increased mortality risk may be due to SCI-specific changes in body composition [6]. Persons with SCI have significantly less fat-free mass and greater fat mass than nondisabled persons [6]. Despite altered body composition, body mass index (BMI) has been a poor and inconsistent predictor of CHD in persons with SCI [11].

Although CVD is a leading cause of death in the population with SCI, an inverse relationship exists between the level of injury and CHD [12], possibly due to relative hypotension. To reduce cardiovascular-related morbidity and mortality, it is important to understand any possible differences in other cardiometabolic risk factors related to the level and completeness of injury. Also, Iranian patients with SCI have very low physical activity levels and poor dietary intake [13]. To our knowledge, a detailed analysis of all cardiometabolic risk factors that also examines the effects of level of injury has yet to be undertaken among patients with SCI. In this study, we analyzed cardiometabolic risk factors in individuals with SCI based on injuryrelated factors.

\section{MATERIALS AND METHODS}

\section{Study Population}

In this cross-sectional study, we assessed 162 patients with SCI from May 2008 to June 2009. Data were collected from patients with SCI referred to the Brain and Spinal Injury Research (BASIR) Center at the Tehran University of Medical Sciences during a $1 \mathrm{~h}$ face-to-face interview. Individuals were included in the study according to the following criteria: motor complete injury between cervical level 5 and thoracic level 12, $\geq 18$ yr old, and $>1$ yr postinjury. Exclusion criteria included pregnancy; lactation; amputation; nontraumatic SCI etiology; history of DM; active decubitus ulcer; thyroid, hepatic, or renal disorders; and neurological disorders other than SCI. The level and completeness of lesion were classified as proposed by Kirshblum et al. [14].

\section{Anthropometric Measurements}

Trained research assistants completed all anthropometric measurements. Each measurement was performed twice and averaged if the individual measurement differed by $\leq 5$ percent. If the difference was $>5$ percent, a third measurement was performed and the two closest measures were averaged. Height and weight were measured, and BMI was calculated using body weight/height squared $\left(\mathrm{kg} / \mathrm{m}^{2}\right)$. Waist circumference (WC) was measured at the level of the lowest rib and classified based on standard classification (male: $>102 \mathrm{~cm}$, female: $>88 \mathrm{~cm}$ ) [15]. Blood pressure (BP) was measured on the right arm in the sitting position after a $5 \mathrm{~min}$ rest by auscultation using a stethoscope twice ( $6 \mathrm{~h}$ interval), and the mean of these was used.

\section{Assessment of Dietary Intake}

A detailed description of the dietary intake assessment has been published in two previous research studies $[13,16]$.

\section{Laboratory Measurements}

Antecubital venous blood samples were taken under antiseptic conditions in the postabsorptive state after an overnight $(12 \mathrm{~h})$ fast. Venous blood samples were collected in empty vacutainer tubes with the exception of those for glucose, which contained anticoagulant. All specimens were centrifuged within 30 to $45 \mathrm{~min}$ after collection at 3,000 rotations per minute. Glucose was measured using the glucose oxydase method using a Pars Azmoon kit (Teif Azmoon Pars Co; Tehran, Iran) [17]. Total cholesterol (TC) [15], HDL-C, and TG levels [18] were determined using an enzymatic colorimetric test (Pars Azmoon kit). LDL-C values were determined using the Friedewald equation [19].

Major risk factors for CHD were determined using the criteria established by the Executive Summary of the Third Report of the National Cholesterol Education Program Expert Panel on Detection, Evaluation, and Treatment of High Blood Cholesterol in Adults (Adult Treatment Panel III) [20].

\section{Statistical Analyses}

The results are reported as mean \pm standard deviation. The limits of statistical significance was $p<0.05$. After evaluating the normality of data using a one-sample Kolmogorov-Smirnov test, numerical variables were compared with a Student $t$-test. Discrete values were compared 
with a chi-squared test. Correlations were computed between the duration of injury and individual CVD risk factors using Pearson and Spearman correlation coefficients for normally and non-normally distributed data, respectively. Linear regression analysis was performed for detecting predictor factors for serum profile. The statistical analysis was performed using SPSS for Windows version 16.0 (IBM Corporation; Armonk, New York).

\section{RESULTS}

A total of 162 patients with SCI participated in the study; Table 1 shows their characteristics. Table 2 presents anthropometric and biochemical data of the patients [21-24]. According to Laughton et al. [21], since a BMI score of $>22$ is overweight and $>25$ is obese, $62.96(n=$ $102)$ and $32.71(n=53)$ percent of the patients in this study were classified as overweight and obese, respectively.

Table 3 compares mean \pm standard deviation for cardiometabolic risk factors in tetraplegic and paraplegic and complete and incomplete groups. BMI, TC, and LDL-C were significantly higher in the paraplegia group than in the tetraplegia group (Table 3). Systolic BP (SBP) was significantly higher in the complete lesion group of patients (Table 3 ).

Time postinjury was correlated directly with $\mathrm{WC}(p=$ $0.04, r=0.16$ ). There was no correlation between time postinjury and other cardiometabolic risk factors.

Table 1.

Participant characteristics $(n=162)$.

\begin{tabular}{lc}
\hline \multicolumn{1}{c}{ Characteristic } & $\boldsymbol{n}(\%)$ or Mean \pm SD \\
\hline Sex & $131(80.9)$ \\
Male & $31(19.1)$ \\
Female & $8.03 \pm 5.75$ \\
Duration of SCI (yr) & \\
Level of SCI & $68(42.0)$ \\
$\quad$ Paraplegia & $94(58.0)$ \\
Tetraplegia & \\
Completeness of Lesion & $48(29.6)$ \\
Complete & $114(70.4)$ \\
Incomplete & $34.17 \pm 8.75$ \\
Age (yr) & $70.08 \pm 13.40$ \\
Weight (kg) & $173.18 \pm 9.14$ \\
Height (cm) & $44(27.2)$ \\
Smoker & \\
SCI = spinal cord injury, SD = standard deviation. & \\
\hline \hline
\end{tabular}

BMI was directly correlated with SBP $(p<0.001, r=$ $0.27)$, serum TG level $(p<0.001, r=0.37)$, serum TC level $(p<0.001, r=0.28)$, serum LDL-C level $(p<0.001$, $r=0.29)$, and WC $(p<0.001, r=0.68)$. BMI showed inverse correlation with HDL-C $(p=0.01, r=-0.24)$. LDL-C was correlated with SBP $(p=0.01, r=0.19)$, and HDL-C showed inverse correlation with diastolic BP $(p=$ $0.02, r=-0.17)$. The lipid profiles did not show any correlation with the neurological level of SCI and completeness of lesions. Fasting blood sugar (FBS) was directly correlated with education $(p=0.01, r=0.23)$.

Hypertension was more frequent in the patients with paraplegia than in those with tetraplegia ( $4.4 \%$ vs $1.1 \%)$, and the percentage of patients $\geq 45 \mathrm{yr}$ old was also greater in those with tetraplegia than those with paraplegia (16.9\% vs $10.5 \%)$. Patients with tetraplegia smoked more (28 vs 16$)$ and had lower HDL-C (67.0\% vs $60.3 \%)$ than those with paraplegia, but the difference was not statistically significant. Table 4 presents the correlation coefficients between dietary intake and lipid profile of patients with SCI.

\section{DISCUSSION}

IGT and DM occur more frequently in persons with SCI than in the nondisabled population [25-26]. Similar to our previous two studies, approximately 13.58 and 3.58 percent of our patients had DM and IGT, respectively $[13,16]$. Duckworth et al. reported a higher prevalence of DM and IGT (23\% and 40\%, respectively) [27]. Studies have shown that the prevalence of IGT and DM are higher in the United States than in countries such as Iran [28-29]; this can also be generalized to subgroups such as patients with SCI.

In our study, 32.7 percent of the patients with SCI were relatively obese. In Demirel et al., patients with SCI had a prevalence of 10 percent for obesity, described as a BMI score $>30$ [8]. Mean BMI values in the studies of persons with long-standing SCI ranged from 20 to 27 $[6,8,30]$. In another study performed at the BASIR Center [16], 20 percent of the patients with SCI had central obesity according to the World Health Organization, significantly in patients with higher age and more time postinjury. There was also a significant positive relationship between the level of injury and BMI, as well as between WC and age and time postinjury. 
Table 2.

Cardiometabolic risk factors in patients with spinal cord injury.

\begin{tabular}{|c|c|c|c|}
\hline Risk Factor and Defining Levels & Mean \pm SD & Frequency (\%) & $\begin{array}{c}\text { Population Not Meeting } \\
\text { Normal Defining Level (\%) }\end{array}$ \\
\hline Body Mass Index [21] & $23.4 \pm 4.3$ & - & - \\
\hline$<22$ (overweight) & - & - & $102(62.9)$ \\
\hline Waist Circumference $(\mathrm{cm})$ [22] & $86.5 \pm 12.4$ & - & - \\
\hline$<102$ (male) & - & - & $16(12.2)$ \\
\hline$<88$ (female) & - & - & $9(29.0)$ \\
\hline Diastolic Blood Pressure $(\leq 80 \mathrm{~mm} \mathrm{Hg})[22]$ & $70.7 \pm 7.6$ & - & - \\
\hline Fasting Blood Sugar (mg/dL) [23] & $92.6 \pm 27.1$ & - & $27(16.7)$ \\
\hline$<100$ (normal) & - & $135(83.3)$ & - \\
\hline 100-125 (impaired) & - & $22(13.6)$ & - \\
\hline$\geq 126$ (diabetes mellitus) & - & $5(3.1)$ & - \\
\hline Total Cholesterol (mg/dL) [24] & $172.6 \pm 40.5$ & - & $36(22.2)$ \\
\hline$<150$ (normal) & - & $106(65.4)$ & - \\
\hline 150-199 (borderline high) & - & $25(15.4)$ & - \\
\hline $200-499$ (high) & - & $30(18.5)$ & - \\
\hline$\geq 500$ (very high) & - & $1(0.6)$ & - \\
\hline HDL-C (mg/dL) [24] & $36.7 \pm 8.5$ & - & - \\
\hline$>40$ (male) & - & - & $94(71.8)$ \\
\hline$>50$ (female) & - & - & $10(32.3)$ \\
\hline LDL-C (mg/dL) [24] & $94.7 \pm 25.7$ & - & $65(40.1)$ \\
\hline$<100$ (optimal) & - & $97(59.9)$ & - \\
\hline $100-129$ (near optimal) & - & $53(32.7)$ & - \\
\hline $130-159$ (borderline high) & - & $8(4.9)$ & - \\
\hline
\end{tabular}

Table 3.

Cardiometabolic risk factors (mean \pm standard deviation) in tetraplegic and paraplegic and complete and incomplete groups of patients with spinal cord injury.

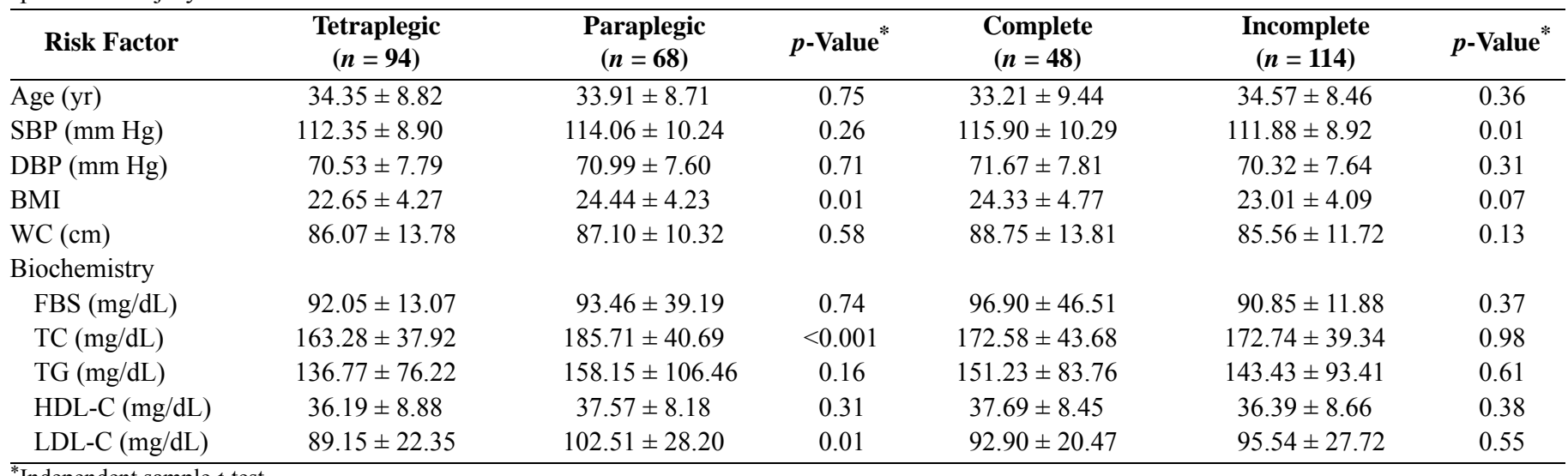

*Independent sample $t$-test.

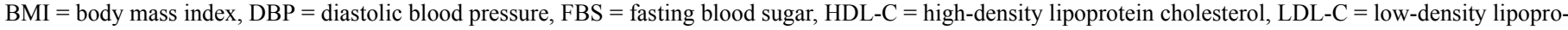
tein cholesterol, $\mathrm{SBP}=$ systolic blood pressure, $\mathrm{TC}=$ total cholesterol, $\mathrm{TG}=$ triglyceride, $\mathrm{WC}=$ waist circumference. 
Table 4.

Correlation between dietary intake and lipid profile of patients with spinal cord injury.

\begin{tabular}{lccccc}
\hline \multicolumn{1}{c}{ Dietary Intake } & LDL-C & HDL-C & TG & TC & FBS \\
\hline Total Energy (kcal) & -0.007 & 0.027 & 0.065 & 0.143 & 0.133 \\
Carbohydrate (g) & 0.028 & -0.008 & 0.091 & 0.148 & 0.094 \\
Fat (g) & -0.084 & 0.058 & 0.021 & 0.061 & 0.134 \\
Saturated Fat (g) & -0.013 & 0.078 & 0.016 & 0.061 & 0.176 \\
Monounsaturated Fat (g) & -0.02 & 0.052 & 0.019 & 0.107 & 0.111 \\
Polyunsaturated Fat (g) & -0.191 & 0.005 & -0.001 & -0.053 & 0.057 \\
Cholesterol (mg) & 0.163 & 0.114 & 0.007 & 0.200 & 0.300 \\
Fiber (g) & 0.127 & 0.070 & 0.083 & 0.154 & 0.049 \\
\hline FBS = fasting blood sugar, HDL-C = high-density lipoprotein cholesterol, \\
LDL-C = low-density lipoprotein cholesterol, TC = total cholesterol, TG = \\
triglyceride.
\end{tabular}

Elevation of LDL-C and depression of HDL-C are two important risk factors for CHD [31-32]. Approximately 10 percent of the U.S. population has an HDL-C value of $<35 \mathrm{mg}$ per $100 \mathrm{~mL}$, whereas about 24 to 40 percent of those with chronic SCI have HDL-C levels below this value [32-33]. Men with SCI may have a greater risk because their HDL-C level is lower. The percentage of individuals with low serum HDL-C level $(<40 \mathrm{mg} / \mathrm{dL})$ is remarkable (71.8\%). Of women, 32.3 percent have HDLC levels of $<50 \mathrm{mg} / \mathrm{dL}$. In the Turkish Heart Study, 53 percent of Turkish men and 26 percent of Turkish women had HDL-C levels of $<35 \mathrm{mg} / \mathrm{dL}$ [34].

In the present study, none of the patients performed regular physical activity. The remarkable percentage of patients with low HDL-C in these patients may be explained by the lower physical activity levels in this group. Other causes of lower HDL-C, such as a high-fat diet [35-37], shown in our previous related study [13], may also contribute to low HDL-C in these patients.

In the general population, about 25 percent of individuals have elevated serum LDL-C levels ( $>130 \mathrm{mg}$ per $100 \mathrm{~mL}$ ) [1]. LDL-C levels of our patients with SCI was 40.1 percent; Bauman et al. reported a nearly similar value of LDL-C (44\%) [36].

In our study, 22.2 percent of patients had a TC of $>200 \mathrm{mg} / \mathrm{dL}$, which is similar to the findings of other studies [27,35]. High TG levels, described as $>150 \mathrm{mg} / \mathrm{dL}$, were present in 34.6 percent of the patients with SCI. Consistent with our findings, Vichiansiri et al. reported high TG levels in 28.9 percent of patients with chronic SCI [37]. Groah et al., in a cross-sectional study of 121 subjects with chronic SCI, showed that 305 had high levels of TG [4].
In the present study, patients with paraplegia were shown to have higher BMI as well as increased levels of serum LDL-C and TC. In Duckworth et al., higher levels of HDL-C were detected in the paraplegia group [38]. In Groah et al., TG levels were similar between the tetraplegic and paraplegic groups [4]. In addition, TC, HDL-C, and LDL-C levels were all nonsignificantly higher in the persons with paraplegia.

Hypertension was present in 2.5 percent of our study population; it was more frequent in those with paraplegia than tetraplegia $(4.4 \%$ vs $1.1 \%)$ but this difference was not statistically significant. However, in Bauman and Spungen, the prevalence of hypertension was 34 percent for both paraplegia and tetraplegia [39]. Increased prevalence of hypertension in persons with paraplegia was found in other studies as well [4,39]. BP was lower in persons with incomplete lesions than in those with complete lesions. Based on our research, there is no study available to compare BP in complete and incomplete patients. However, a possible reason for that is elevation due to autonomic dysreflexia at the time BP was recorded [11]. On the other hand, there remains a relationship between increased BMI levels and higher BP [11].

A total of 27.2 percent of the patients were current cigarette smokers, compared with 34 percent in Bauman and Spungen [39]. In Iran, there are poor options for transportation and sports facilities available for persons with SCI. Therefore, they have low activity levels, and perhaps this is the main reason for obesity and other abnormal cardiometabolic risk factors. With the improvement of transportation and sports facilities, persons with SCI would find more chances to increase their daily activity levels and reduce cardiometabolic risks.

We found no correlation between time postinjury and other cardiometabolic risk factors. Whereas in Demirel et al., the adverse risk profile of increased $\mathrm{TC}$ and the ratios of TC to HDL-C and LDL-C to HDL-C were more common with time postinjury $>12 \mathrm{mo}$, and there was a negative correlation between HDL-C and time postinjury [8]. When HDL-C levels decrease, SBP rises, and when LDL-C levels rise, SBP also rises. Similar in Reaven [40], obesity was associated with hypertension and increased levels of TC, TG, and LDL-C levels in our study. HDL-C showed inverse correlation with the time postinjury, TG, and TC to HDL-C and LDL-C to HDL-C ratios in Demirel et al. [8]. Similar to another study [20], an inverse relationship was present between BMI and serum HDL-C levels and a direct relationship was noted 
between BMI and serum TG levels in this study. We found a positive correlation between saturated fat intake and FBS, and also between cholesterol intake and LDLC. Relating to our previous study [13], the diets of individuals with SCI did not meet dietary guidelines [13], and the intakes of total fat and saturated fat $(38 \%$ and $12.8 \%$, respectively) were high. Therefore, the dietary intakes in patients with SCI were corrected and standard interventions were applied for reducing cardiometabolic risk factors.

\section{CONCLUSIONS}

Persons with paraplegia may have increased hypertension, higher BMI, and increased levels of serum LDL$\mathrm{C}$ and TC levels. Of our patients with SCI, 13.58 percent had DM, 32.71 percent were obese, 71.8 percent had low HDL-C, 40.1 percent had high LDL-C, 34.6 percent had high TG, and 22.2 percent had high TC. Individuals with SCI must receive nutrition consultation and exercise encouragement to reduce cardiometabolic risk factors.

\section{ACKNOWLEDGMENTS}

\author{
Author Contributions: \\ Study concept and design: H. Sabour, A. N. Javidan, M. R. Vafa. \\ Analysis and interpretation of data: Z. Khazaeipour. \\ Drafting of manuscript: N. Ranjbarnovin. \\ Critical revision of manuscript for important intellectual content: \\ H. Sabour. \\ Statistical analysis: Z. Khazaeipour. \\ Technical and material support: F. Ghaderi, F. K. Mehrabani. \\ Study supervision: F. Shidfar.
}

Financial Disclosures: The authors have declared that no competing interests exist.

Funding/Support: This material was unfunded at the time of manuscript preparation.

Institutional Review: The protocol was approved by the Ethics Committee at Tehran University of Medical Sciences. Written informed consent was obtained from each patient.

Participant Follow-up: The authors do not plan to inform participants of the publication of this study.

\section{REFERENCES}

1. Bauman WA, Spungen AM. Coronary heart disease in individuals with spinal cord injury: assessment of risk factors.
Spinal Cord. 2008;46(7):466-76. [PMID:18180789]

http://dx.doi.org/10.1038/sj.sc.3102161

2. Ford ES, Giles WH, Dietz WH. Prevalence of the metabolic syndrome among US adults: findings from the third National Health and Nutrition Examination Survey. JAMA. 2002;287(3):356-59. [PMID:11790215]

http://dx.doi.org/10.1001/jama.287.3.356

3. Haffner SM. Obesity and the metabolic syndrome: the San Antonio Heart Study. Br J Nutr. 2000;83(Suppl 1):S67-70. [PMID:10889794] http://dx.doi.org/10.1017/S0007114500000970

4. Groah SL, Nash MS, Ward EA, Libin A, Mendez AJ, Burns P, Elrod M, Hamm LF. Cardiometabolic risk in communitydwelling persons with chronic spinal cord injury. J Cardiopulm Rehabil Prev. 2011;31(2):73-80. [PMID:21045711]

5. Spungen AM, Wang J, Pierson RN Jr, Bauman WA. Soft tissue body composition differences in monozygotic twins discordant for spinal cord injury. J Appl Physiol. 2000; 88(4):310-15. [PMID:10749824]

6. Spungen AM, Adkins RH, Stewart CA, Wang J, Pierson RN Jr, Waters RL, Bauman WA. Factors influencing body composition in persons with spinal cord injury: a crosssectional study. J Appl Physiol. 2003;95(6):2398-2407. [PMID:12909613]

7. Bauman WA, Spungen AM. Carbohydrate and lipid metabolism in chronic spinal cord injury. J Spinal Cord Med. 2001; 24(4):266-77. [PMID:11944785]

8. Demirel S, Demirel G, Tükek T, Erk O, Yilmaz H. Risk factors for coronary heart disease in patients with spinal cord injury in Turkey. Spinal Cord. 2001;39(3):134-38.

[PMID:11326322] http://dx.doi.org/10.1038/sj.sc.3101135

9. Schmid A, Halle M, Stützle C, König D, Baumstark MW, Storch MJ, Schmidt-Trucksäss A, Lehmann M, Berg A, Keul J. Lipoproteins and free plasma catecholamines in spinal cord injured men with different injury levels. Clin Physiol. 2000;20(4):304-10. [PMID:10886263] http://dx.doi.org/10.1046/j.1365-2281.2000.00263.x

10. Nesto RW. Beyond low-density lipoprotein: addressing the atherogenic lipid triad in type 2 diabetes mellitus and the metabolic syndrome. Am J Cardiovasc Drugs. 2005;5(6): 379-87. [PMID:16259526] http://dx.doi.org/10.2165/00129784-200505060-00005

11. Weaver FM, Collins EG, Kurichi J, Miskevics S, Smith B, Rajan S, Gater D. Prevalence of obesity and high blood pressure in veterans with spinal cord injuries and disorders: a retrospective review. Am J Phys Med Rehabil. 2007; 86(1):22-29. [PMID:17304685] http://dx.doi.org/10.1097/PHM.0b013e31802b8937

12. Yekutiel M, Brooks ME, Ohry A, Yarom J, Carel R. The prevalence of hypertension, ischaemic heart disease and diabetes in traumatic spinal cord injured patients and 
amputees. Paraplegia. 1989;27(1):58-62. [PMID:2784200] http://dx.doi.org/10.1038/sc.1989.9

13. Sabour H, Javidan AN, Vafa MR, Shidfar F, Nazari M, Saberi H, Rahimi A, Emami Razavi H. Calorie and macronutrients intake in people with spinal cord injuries: an analysis by sex and injury-related variables. Nutrition. 2012;28(2):143-47. [PMID:21872437]

http://dx.doi.org/10.1016/j.nut.2011.04.007

14. Kirshblum SC, Burns SP, Biering-Sorensen F, Donovan W, Graves DE, Jha A, Johansen M, Jones L, Krassioukov A, Mulcahey MJ, Schmidt-Read M, Waring W. International standards for neurological classification of spinal cord injury (revised 2011). J Spinal Cord Med. 2011;34(6):535-46. [PMID:22330108] http://dx.doi.org/10.1179/204577211X13207446293695

15. Buchholz AC, McGillivray CF, Pencharz PB. Differences in resting metabolic rate between paraplegic and able-bodied subjects are explained by differences in body composition. Am J Clin Nutr. 2003;77(2):371-78. [PMID:12540396]

16. Sabour H, Javidan AN, Vafa MR, Shidfar F, Nazari M, Saberi H, Rahimi A, Razavi HE. Obesity predictors in people with chronic spinal cord injury: an analysis by injury related variables. J Res Med Sci. 2011;16(3):335-39. [PMID:22091254]

17. Azadbakht L, Esmaillzadeh A. Dietary and non-dietary determinants of central adiposity among Tehrani women. Public Health Nutr. 2008;11(5):528-34. [PMID:17764604] http://dx.doi.org/10.1017/S1368980007000882

18. Esmaillzadeh A, Mirmiran P, Azizi F. Whole-grain consumption and the metabolic syndrome: a favorable association in Tehranian adults. Eur J Clin Nutr. 2005;59(3):353-62.

[PMID:15536473] http://dx.doi.org/10.1038/sj.ejen.1602080

19. Friedewald WT, Levy RI, Fredrickson DS. Estimation of the concentration of low-density lipoprotein cholesterol in plasma, without use of the preparative ultracentrifuge. Clin Chem. 1972;18(6):499-502. [PMID:4337382]

20. Expert Panel on Detection, Evaluation, and Treatment of High Blood Cholesterol in Adults. Executive Summary of The Third Report of The National Cholesterol Education Program (NCEP) Expert Panel on Detection, Evaluation, And Treatment of High Blood Cholesterol In Adults (Adult Treatment Panel III). JAMA. 2001;285(19):2486-97. [PMID:11368702] http://dx.doi.org/10.1001/jama.285.19.2486

21. Laughton GE, Buchholz AC, Martin Ginis KA, Goy RE; SHAPE SCI Research Group. Lowering body mass index cutoffs better identifies obese persons with spinal cord injury. Spinal Cord. 2009;47(10):757-62.

[PMID:19350042] http://dx.doi.org/10.1038/sc.2009.33
22. Janssen I, Katzmarzyk PT, Ross R. Body mass index, waist circumference, and health risk: evidence in support of current National Institutes of Health guidelines. Arch Intern Med. 2002;162(18):2074-79. [PMID:12374515] http://dx.doi.org/10.1001/archinte.162.18.2074

23. Expert Committee on the Diagnosis and Classification of Diabetes Mellitus. Report of the expert committee on the diagnosis and classification of diabetes mellitus. Diabetes Care. 2003;26(Suppl 1):S5-20. [PMID:12502614] http://dx.doi.org/10.2337/diacare.26.2007.S5

24. Lee MY, Myers J, Hayes A, Madan S, Froelicher VF, Perkash I, Kiratli BJ. C-reactive protein, metabolic syndrome, and insulin resistance in individuals with spinal cord injury. J Spinal Cord Med. 2005;28(1):20-25. [PMID:15832900]

25. Bauman WA, Spungen AM. Disorders of carbohydrate and lipid metabolism in veterans with paraplegia or quadriplegia: a model of premature aging. Metabolism. 1994;43(6): 749-56. [PMID:8201966] http://dx.doi.org/10.1016/0026-0495(94)90126-0

26. Bauman WA, Adkins RH, Spungen AM, Waters RL. The effect of residual neurological deficit on oral glucose tolerance in persons with chronic spinal cord injury. Spinal Cord. 1999;37(11):765-71. [PMID:10578247]

http://dx.doi.org/10.1038/sj.sc.3100893

27. Duckworth WC, Jallepalli P, Solomon SS. Glucose intolerance in spinal cord injury. Arch Phys Med Rehabil. 1983; 64(3):107-10. [PMID:6338859]

28. World Health Organization. Global health risks: Mortality and burden of disease attributable to selected major risks. Geneva (Switzerland): World Health Organization; 2009.

29. World Health Organization. Definition and diagnosis of diabetes mellitus and intermediate hyperglycemia: Report of a WHO/IDF consultation. Geneva (Switzerland): World Health Organization; 2006.

30. Jones LM, Legge M, Goulding A. Healthy body mass index values often underestimate body fat in men with spinal cord injury. Arch Phys Med Rehabil. 2003;84(7):1068-71. [PMID:12881836] http://dx.doi.org/10.1016/S0003-9993(03)00045-5

31. Castelli WP, Leaf A. Identification and assessment of cardiac risk factors overview. Cardiol Clin. 1985;3:171-78.

32. Grundy SM, Goodman DW, Rifkind BM, Cleeman JI. The place of HDL in cholesterol management. A perspective from the National Cholesterol Educational Program. Arch Intern Med. 1989;149(3):505-10. [PMID:2645842] http://dx.doi.org/10.1001/archinte.1989.00390030011003

33. Campbell PJ, Mandarino LJ, Gerich JE. Quantification of the relative impairment in actions of insulin on hepatic glucose production and peripheral glucose uptake in non-insulindependent diabetes mellitus. Metabolism. 1988;37(1):15-21. [PMID:3275857] http://dx.doi.org/10.1016/0026-0495(88)90023-6 
34. Mahley RW, Palaoğlu KE, Atak Z, Dawson-Pepin J, Langlois AM, Cheung V, Onat H, Fulks P, Mahley LL, Vakar F, et al. Turkish Heart Study: lipids, lipoproteins, and apolipoproteins. J Lipid Res. 1995;36(4):839-59.

[PMID:7616127]

35. Washburn RA, Figoni SF. High density lipoprotein cholesterol in individuals with spinal cord injury: the potential role of physical activity. Spinal Cord. 1999;37(10):685-95. [PMID:10557124]

http://dx.doi.org/10.1038/sj.sc.3100917

36. Bauman WA, Spungen AM, Zhong YG, Rothstein JL, Petry $\mathrm{C}$, Gordon SK. Depressed serum high density lipoprotein cholesterol levels in veterans with spinal cord injury. Paraplegia. 1992;30(10):697-703. [PMID:1448297] http://dx.doi.org/10.1038/sc.1992.136

37. Vichiansiri R, Saengsuwan J, Manimmanakorn N, Patpiya S, Preeda A, Samerduen K, Poosiripinyo E. The prevalence of dyslipidemia in patients with spinal cord lesion in Thailand. Cholesterol. 2012;2012:847462. [PMID:22848801] http://dx.doi.org/10.1155/2012/847462

38. Duckworth WC, Solomon SS, Jallepalli P, Heckemeyer C, Finnern J, Powers A. Glucose intolerance due to insulin resistance in patients with spinal cord injuries. Diabetes. 1980;29(11):906-10. [PMID:7429029]
39. Bauman WA, Spungen AM. Risk assessment for coronary heart disease in a veteran population with spinal cord injury. Top Spinal Cord Inj Rehabil. 2007;12(4):35-53. http://dx.doi.org/10.1310/sci1204-35

40. Reaven GM. Banting lecture 1988. Role of insulin resistance in human disease. Diabetes. 1988;37(12):1595-1607. [PMID:3056758]

Submitted for publication January 27, 2012. Accepted in revised form November 28, 2012.

This article and any supplemental material should be cited as follows:

Sabour H, Javidan AN, Ranjbarnovin N, Vafa MR, Khazaeipour Z, Ghaderi F, Mehrabani FK, Shidfar F. Cardiometabolic risk factors in Iranians with spinal cord injury: Analysis by injury-related variables. J Rehabil Res Dev. 2013;50(5):635-42.

http://dx.doi.org/10.1682/JRRD.2012.01.0020

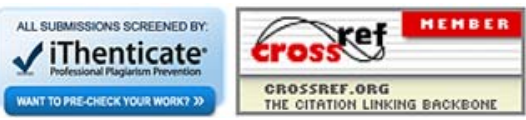

